\title{
Answering mental health questions with reliable research evidence
}

\begin{abstract}
The problem
Finding answers to questions that arise in every day clinical practice has always been an arduous task. The time and effort that it takes to interrogate the wide range of information resources that are now available is rarely rewarded with a gold nugget of evidence. It seems that every new week brings a new journal or web site that promises to solve our problems of information overload, when in reality these new resources often add to our sense of confusion as to where to start searching.
\end{abstract}

\section{Where do we go to answer our questions?}

We have previously introduced readers to the concept of clinical question formulation as the essential first step of evidence-based practice. ${ }^{1}$ Having formulated our clinical question, there are generally 4 places that we go to find an answer?

- Ask a colleague or expert

- Look in a recent textbook

- Search your personal reprint file

- Use an electronic database.

Asking a colleague or expert is often the first option as these people tend to be accessible and easy to approach. Unfortunately, responses from individuals sometimes tend to be loaded with various biases, and should therefore be treated cautiously. Recent textbooks also provide useful lists of references, although these are often out of date before they are published. ${ }^{3}$ There are now new types of textbooks available that are regularly updated to provide us with the best available evidence about prevention and treatment of clinical conditions. One such publication is Clinical Evidence from the BMJ Publishing Group; a new bi-annual, updated compendium of evidence on the effects of common clinical interventions, with issue one containing 8 mental health topics. ${ }^{4}$

Electronic databases have therefore become the primary source of reliable research evidence for the busy mental health professional; but that is in no sense the end of the story because the quality of databases varies widely, both in the type of information indexed and in the versatility and user friendliness of the interface. The largest biomedical database in the world is the US National Library of Medicine's Medline, which is now available for free on the internet as PubMed. ${ }^{5}$ This is undeniably a fantastic resource for health professionals and patients alike, but it does have various drawbacks for the busy clinician looking for a quick answer. Medline indexes about 4000 journals worldwide and most searches will therefore find many papers relevant to the question asked. The complex way in which material is indexed on Medline can also lead to problems as the searcher will often need to have a good deal of searching experience if he is to complete an accurate search, making best use of a combination of thesaurus and freetext terms. Quality filters can often be imposed on searches; indeed, the new clinical queries interface provides an excellent way of limiting your search to particular types of study design (treatment, diagnosis, prognosis, and aetiology) ${ }^{6}$ using methodological filters developed by Haynes $e t$ al. ${ }^{7}$ Furthermore, the US National Institutes of Health have recently put forward a new proposal for a web site called
PubMed Central. This will be a "web-based repository for barrier-free access to primary reports in the life sciences." However, the bottom line is that the Medline searcher, having spent some considerable time wading through the sea of clinical research, is at best left with an article that may contain the answer to his question. An article must then be obtained in full text, critically appraised for validity, reliability, and applicability, and only then used to inform practice.

Various other electronic resources have been developed over the past few years in an attempt to solve these problems. One such resource is the Cochrane Library, ${ }^{9}$ which has become the first site in which to look for evidence on the effectiveness of health care. The Cochrane Library contains a large amount of information relevant to mental health (126 full text systematic reviews, 74 protocols, and over 150000 references to controlled trials $)^{10}$ and is therefore the first place to start any systematic literature search dealing with treatment. The very nature of the database, however, means that it is often rather unwieldy to use and slow to interrogate, with clinical bottom line answers not always being readily available.

\section{Evidence-Based Mental Health online}

The rise of secondary publication journals goes a long way to solving this problem. Evidence-Based Mental Health and its sister journals in other specialties are designed to help to keep health professionals up to date with the latest quality research, providing abstracted information that is easy to digest, with clinical bottom line information in a standard user friendly format. This is obviously a useful updating device, but without a searchable archive of answers it quickly becomes difficult to use. We therefore decided to give the current Evidence-Based Mental Health web site a complete overhaul, building in the following features:

- User friendly, searchable database of complete full text with downloadable PDF (portable document format) files, which can be viewed using a free piece of software called Adobe Acrobat Reader. ${ }^{11}$ This means that you can easily download and view the full text of each article in exactly the same format as it is printed in the paper version of the journal

- Customised search options including browsing by topic or subject. Go directly to the evidence you require or browse through the journal as you would do with the paper version

- Detailed links to an interactive glossary, including a clinical calculator to help you to work out clinical bottom line information

- Links to primary papers

- Full purpose and procedure information

- Letters and debate

- Evaluation section.

EBMH-online.com has been available from January 2000 on a free access basis to everyone. From 1 June 2000 it will be available on a subscription basis. Subscribers to the paper version of the journal will be allocated passwords and also receive access to the web version at no extra cost. Future subscribers will be able to choose whether they receive both paper and electronic 
versions or just the electronic one at a reduced subscription rate. As always, we are keen to find out what our readers think of these new developments as we hope to build a web site that really meets your needs.

\section{National electronic library for mental health}

The new Evidence-Based Mental Health web site will play an important part in the development of the Mental Health section of the National electronic Library for Health $(\mathrm{NeLH}) .^{12}$ The NeLH is a new initiative, announced in the UK government's information for health strategy. It aims to provide easy access to best current knowledge and improve health and health care, clinical practice, and patient choice. The structure of the NeLH can be described by using a building metaphor, with the library having several floors:

- The atrium: help desks for the NeLH

- The know-how floor: guidelines and audit

- The knowledge floor

- The knowledge management floor.

There used to be a fifth floor (the patient information floor) and NHS Direct Online ${ }^{13}$ will now provide this. Mental health topics in the early version of this service include: Alzheimer's disease, bipolar disorder, dementia, post-traumatic stress disorder, and schizophrenia.

The NeLH will also link in to various virtual branch libraries, focusing on the particular needs of different groups. There will be virtual libraries for mental health, learning disabilities, primary care, social services, etc.

The National electronic Library for Mental Health (NeLMH) will be one of the first virtual branch libraries to be developed as this is a key area of health improvement identified by the recent UK government's national service framework for mental health. ${ }^{10}$ One of the main short term aims of the NeLMH will be to provide easy access to best current knowledge within 15 seconds for clinicians and within 3 clicks for patients, and it will therefore benefit from the model set by Evidence-Based Mental Health. It will follow the basic principles set down by the NeLH, so it will be:

- Obsessed with the quality of knowledge

- Concerned with both knowledge and the skills to manage and apply that knowledge

- Equally open to patients and clinicians

- Able to create and sustain communities of users.

The principle users of the NeLMH will have a diverse range of needs. The architecture of the library will take this into account, delivering fast access to knowledge for:
- Patients with mental health problems

- Carers

- General practitioners

- Community psychiatric nurses

- Specialist mental health staff

- Commissioners of health care.

There will be a demonstration version of the NeLMH gateway available on the internet by March $2000 .^{14}$

\section{Conclusion}

As the body of research evidence grows (5500 papers relevant to mental health published every year ${ }^{15}$ ) mental health professionals will become more dependent on electronic information retrieval systems as they endeavour to make their practice as evidence based as possible. Lack of time and financial pressure will mean that reliable "fast answer" knowledge interfaces will become the first port of call for most clinical questions. We must work together to ensure that these systems are developed to meet the needs of all users, providing access to high quality mental health evidence for all.

ANDRÉ TOMLIN

Director of Knowledge Services, Centre for Evidence Based Mental Health Email:andre.tomlin@psych.ox.ac.uk

1 Geddes J. Asking structured and focused clinical questions: essential first step of evidence-based practice [EBMH notebook]. Evidence-Based Mental Health 1999 May;2:35-6.

2 Oxman AD, Sackett DL, Gyatt GH. Users' guides for the medical literature-introduction, 1999. http://www.cche.net/principles/content_ intro.asp

3 Antman EM, Lau J, Kupelnick B, et al. A comparison of results of meta-analyses of randomized control trials and recommendations of clinical experts. Treatments for myocardial infarction. JAMA 1992;268:240-8.

4 Clinical Evidence, 1999. http://www.evidence.org/index-welcome.htm

5 PubMed, 1999. http://www.ncbi.nlm.nih.gov/pubmed

6 PubMed, clinical queries using research methodology filters, 1999. http:// www.ncbi.nlm.nih.gov:80/entrez/query/static/clinical.html

7 PubMed table for clinical queries using research methodology filters, 1999. http://www.ncbi.nlm.nih.gov/PubMed/clinicaltable.html

8 PubMed Central, 1999. http://www.nih.gov/welcome/director/ pubmedcentral/pubmedcentral.htm

9 Cochrane Library, 1999. http://www.update-software.com/ccweb/ cochrane/revabstr/ccabout.htm

10 Department of Health. National service framework for mental health modern standards and service models. London: DoH, 1999. http://www.doh.gov.uk/ nsf/mentalhealth.htm\#fulldoc

11 Get Adobe Acrobat Reader, 1999. http://www.adobe.co.uk/products/ acrobat/readstep.html

12 The National electronic Library for Health, 1999. http://www.nelh.nhs.uk

13 NHS Direct Online 1999. http://www.nhsdirect.nhs.uk

14 The National electronic Library for Mental Health, 1999. http:// www.psychiatry.ox.ac.uk/cebmh/nelmh

15 Geddes J, Reynolds S, Streiner D, et al. Evidence-Based Mental Health-the first year [EBMH notebook] Evidence-Based Mental Health 1999 Feb;2:4-5. 